УДК 37.026

13.00.00 Педагогические науки

ПРОБЛЕМА ИНДИВИДУАЛИЗАЦИИ
ОБУЧЕНИЯ В СОВРЕМЕННЫХ УСЛОВИЯХ

Скибина Яна Владимировна

Старший преподаватель кафедры

информационных систем

РИНЦ SPIN-код: 5252-4411

yanaskibina@yandex.ru

Кубанский государственный аграрный

университет, Краснодар, Россия

Одним из приоритетных направлений

модернизации современного образования является его установка на развитие индивидуальности учащихся. Развитие индивидуальности учащихся предполагает реализацию дидактического принципа индивидуализации обучения. В работе на основе анализа основных исторических и современных определений понятия «индивидуализация обучения» выделены следующие функции индивидуализации обучения: адаптационная, развивающая, реализации. На основе выделенных функций уточнено содержание понятия «индивидуализация обучения» в современных условиях. В связи с тем, что индивидуализация обучения в старшей школе согласуется с возрастными особенностями старшеклассников, разработка вопросов индивидуализации обучения на старшей ступени общего образования приобретает особую актуальность. На основе выделенных функций уточнены цели индивидуализации обучения на старшей ступени общего образования

Ключевые слова: ДИДАКТИЧЕСКИЙ ПРИНЦИП; ИНДИВИДУАЛИЗАЦИЯ;

ИНДИВИДУАЛИЗАЦИЯ ОБУЧЕНИЯ; ПРИНЦИП

ОБУЧЕНИЯ; СТАРШАЯ СТУПЕНЬ ОБЩЕГО

ОБРАЗОВАНИЯ; СТАРШИЙ ШКОЛЬНЫЙ

ВОЗРАСТ; ЦЕЛИ ИНДИВИДУАЛИЗАЦИИ ОБУЧЕНИЯ

Doi: 10.21515/1990-4665-123-142
UDC 37.026

Pedagogical sciences

\section{THE PROBLEM OF INDIVIDUALIZATION IN TEACHING IN MODERN CONDITIONS}

Skibina Yana Vladimirovna

Senior lecturer of department

of information systems

RSCI SPIN-code: 5252-4411

yanaskibina@yandex.ru

Kuban State Agrarian University,

Krasnodar, Russia

One of the main trends of the modern education modernization is its aim to develop the students' individuality. The development of the students' individuality assumes implementation of an individualization principle in teaching. In this work, on the basis of the analysis of main historical and modern definitions of a concept «individualization in teaching» we have identified the following functions: adaptation, developing, realization. Based on these functions the maintenance of the concept of individualization in teaching is specified in modern conditions. The development of the individualization in teaching issues is particularly relevant at a higher degree of basic education, because the individualization of learning at the senior high school is consistent with the age peculiarities of senior high school students. Because of the identified functions, purposes of individualization in teaching at a higher degree of basic education are specified

Keywords: DIDACTIC PRINCIPLE; INDIVIDUALIZATION; INDIVIDUALIZATION IN TEACHING; PRINCIPLE IN TEACHING; HIGHER DEGREE OF GENERAL EDUCATION; SECONDARY SCHOOL AGE; PURPOSES OF INDIVIDUALIZATION IN TEACHING

\footnotetext{
Обновленные образовательные стандарты ориентируют современную систему образования на раскрытие индивидуальности, развитие сущностных сил личности, удовлетворение образовательных потребностей обучающихся, свободу выбора индивидуальной траектории в образовании, развитие творческих способностей, становление системы
} 
вариативного образования. Направленность на расширение спектра индивидуальных образовательных возможностей актуализирует исследования в области индивидуализации обучения, в том числе на старшей ступени общего образования.

Изучение литературных источников, посвященных вопросам индивидуализации обучения, выявило существование нескольких подходов к пониманию сущности индивидуализации обучения. В результате была поставлена следующая задача - на основе анализа различных трактовок определения «индивидуализации обучения» уточнить содержание данного понятия.

Индивидуализация обучения (индивидуальный подход в обучении) добавляется в систему основных дидактических принципов в середине 60-х гг. XX века. Е.С. Рабунский дал этому принципу следующее определение [17, с. 95]: 1) индивидуальный подход к школьникам означает частичное, временное изменение ближайших целей, отдельных сторон содержания, методов и организационных форм учебно-воспитательной работы с учетом индивидуальных особенностей личности ученика для реализации наиболее успешного развития ее социальной типичности и индивидуального своеобразия; 2) индивидуальный подход в учебном процессе представляет собой действенное внимание к каждому ученику, его индивидуальным особенностям в условиях коллективного обучения, предлагает разумное сочетание общеклассных, групповых и индивидуальных занятий для повышения качества обучения и развития каждого ученика.

В приведенном определении суть принципа индивидуализации обучения состоит в адаптации системы обучения к индивидуальным особенностям учащихся. Первоначально такая трактовка принципа индивидуализации обучения была связана с поиском путей предупреждения и преодоления неуспеваемости учащихся. В этом 
направлении проведено большое количество психолого-педагогических исследований, в том числе А.А. Бударным, которым предложен комплексный дидактический и психологический подход к преодолению проблемы неуспеваемости путем индивидуализации обучения [7, с. 24]. Идеи индивидуализации обучения способствовали развитию в 60-70-х гг. $\mathrm{XX}$ века специального учебного метода - метода программированного обучения, одной из ключевых идей которого также стала идея адаптации системы обучения к индивидуальным особенностям учащихся. В его контексте под индивидуализацией обучения понимали обеспечение различного темпа учебной работы школьников в соответствии с их способностями [7, с. 30].

Параллельно с «идеей адаптации» концепция индивидуализации обучения дополняется «идеей развития». Так, например, В.А. Крутецкий, отмечая зависимость эффективности обучения от учета индивидуальных психологических особенностей учащихся, призывая на практике ориентироваться на реальные типы учеников, а не на мифического «среднего» ученика, подчеркивал, что не обучение должно подстраиваться под индивидуальные особенности учащихся, a, наоборот, учащиеся должны подстраиваться под постепенно усложняющийся и убыстряющийся процесс обучения. Он ориентировал индивидуальный подход в обучении не только на ликвидацию пробелов, но и на работу по развитию мотивации, мышления, познавательных интересов, способностей учащихся. Кроме того, исследователь отмечал, что при индивидуальном подходе не только слабоуспевающим ученикам должно быть оказано внимание учителя, но и тем, кто обнаруживает высокий уровень одаренности в той или иной предметной области, проявляет ярко выраженные склонности, способности и интересы к тем или иным видам учебной деятельности [9]. Таким образом, в индивидуализации обучения 
начинают видеть один из факторов не только эффективного обучения, но и успешного развития учащихся.

В 70-80-е гг. ХХ века активно формируется концепция развивающего обучения, согласно которой именно в процессе развития зарождаются, формируются и проявляются индивидуальные особенности, индивидуальное своеобразие каждой личности, ее оригинальность, неповторимость. Именно в русле концепции развивающего обучения развернулось исследование вопросов индивидуализации и дифференциации обучения И.Э. Унт [19]. В данной работе представлены как адаптационная, так и развивающая функции индивидуализации обучения. Определяя индивидуализацию обучения как учет в процессе обучения индивидуальных особенностей учащихся во всех его формах и методах, независимо от того, какие особенности и в какой мере учитываются, И.Э. Унт подчеркивала, что индивидуализация обучения является необходимым фактором реализации разнообразных целей обучения (обучающих, развивающих, воспитывающих) и формирования индивидуальности. Исследователь отмечала, что индивидуализация обучения необходима, во-первых, для выявления актуального уровня развития учащихся, но, кроме того, должна осуществляться в течение всего периода обучения, так как развивающее обучение не ведет к сглаживанию уровней развития.

В связи с распространением идей развивающего обучения, а также усиливающимися гуманистическими образовательными тенденциями в 80-е гг. ХX века происходит наполнение новым содержанием целевого образовательного компонента. В целях обучения выделяют два равнозначных аспекта: предметный и личностный [2]. В свете новых образовательных тенденций проведено исследование А.А. Кирсановым, в котором отражены идеи, как развивающего обучения, так и только формирующегося личностно-ориентированного подхода. Исследователь 
постулировал установку обучения на максимальное развитие индивидуальности учащихся. Утверждая, что воспитание индивидуальности требует индивидуального подхода, автор ориентировал индивидуализацию на целостную личность школьника, целостный учебный процесс. А.А. Кирсанов определил индивидуализацию учебной деятельности как систему индивидуализированных способов и приемов взаимообусловленных действий учителя и учащихся, которая органично, как характерологическая сторона (признак) присуща всем этапам учебной деятельности. По мнению исследователя, основой реализации принципа индивидуализации учебной деятельности выступает всестороннее изучение индивидуальных особенностей учащихся, а основной целью создание условий для успешного осуществления каждым учащимся ближайших (формирование предметных знаний, умений, навыков) и отдаленных целей учебной деятельности (развитие личностных качеств). А.А. Кирсанов сформулировал ряд тезисов, существенно дополнивших концепцию индивидуализации обучения. Рассматриваемый принцип ориентирует обучение, как на актуальные возможности, так и на потенциальный уровень развития учащихся (не приспособление обучения к уровню подготовленности и развития ученика, а систематическое, целенаправленное, последовательное развитие его потенциальных возможностей до объективных требований); способствует комплексному обучающему, развивающему, воспитывающему воздействию на целостную личность учащихся [7].

Следует отметить, что, несмотря на обогащение концепции индивидуализации обучения «идеей развития», адаптационная функция данного принципа также не утратила своего значения. Так, например, Р.С. Черкасов, А.А. Столяр определили индивидуальный подход в обучении как приспособление обучения либо к содержанию и уровню знаний, умений и навыков каждого учащегося, либо также к характерным для 
него особенностям процесса усвоения, либо даже к некоторым устойчивым особенностям его личности [12]. А И.П. Подласый видел реализацию данного принципа не в приспособлении целей и основного содержания обучения и воспитания к отдельному ученику, а в приспособлении форм и методов педагогического воздействия к его индивидуальным особенностям с тем, чтобы обеспечить запроектированный уровень развития личности [14].

В 90-е гг. ХХ века появляется термин «личностно-ориентированное образование», начинают формироваться личностно-ориентированные образовательные концепции. При этом, индивидуализация обучения выступает фундаментом построения личностно-ориентированного образования [13]. В этой связи происходит актуализация психологопедагогических исследований в области индивидуализации обучения.

Анализируя современные диссертационные исследования по вопросам индивидуализации обучения, можно отметить, что ряд авторов понимают принцип индивидуализации обучения как организацию обучения, направленную на учет и развитие индивидуальных особенностей учащихся, другими словами, выделяют адаптационную и развивающую функции принципа индивидуализации обучения. Например, приводятся следующие определения:

- индивидуализация современного обучения представляет собой средство развития индивидуальных способностей обучаемых на различных уровнях потенциальных возможностей [10];

- индивидуализация обучения понимается как организация учебного процесса, предусматривающая и деятельность учителя, и деятельность ученика, при которой выбор способов, приемов, темпа учебной деятельности обусловлен уровнем учебной готовности школьников [21];

- под индивидуально-дифференцированным подходом подразумевается система диагностических процедур по изучению 
личности ученика и связанная с ней система дидактических способов развития этой личности с учетом существенных для учения индивидуально-психологических особенностей [8];

- индивидуализация обучения предполагает профессиональное, научно обоснованное диагностирование индивидуально-психологических особенностей каждого обучающегося и создание условий для максимального развития его личностного потенциала [5];

- под индивидуализацией понимается организация учебного процесса, при которой выбор способов, приемов, темпа обучения учитывает индивидуальные различия учащихся, уровень развития их способностей к учению [11].

С другой стороны, под влиянием идей активно развивающихся с конца XX века системно-деятельностного и компетентностного подходов, ориентирующих систему образования не столько на формирование предметных знаний, умений, навыков, сколько на формирование общеучебных умений, на развитие самостоятельности учебных действий, формирование способности учащихся действовать в конкретных жизненных ситуациях, в трактовке принципа индивидуализации обучения прослеживается новая функция - функция реализации. В современных диссертационных исследованиях приводятся следующие определения индивидуализации обучения:

- под индивидуализацией обучения понимается организация учебного процесса с учётом индивидуальных особенностей учащихся, позволяющая создать оптимальные условия для реализации потенциальных возможностей каждого ученика $[1,3,15,20]$;

- индивидуализация - это движущая сила, содействующая самоопределению, самореализации и саморазвитию старшеклассников в самообучении [6]; 
- под индивидуализацией образовательного процесса в широком контексте понимается способ обеспечения каждому школьнику права и возможности на формирование собственных образовательных целей и задач, собственной образовательной траектории, придание осмысленности учебному действию за счёт возможности выбора типа действия, привнесения личных смыслов, заказа к своему образованию, видения своих учебных и образовательных перспектив [18].

Таким образом, в современных условиях индивидуализация обучения представляет собой динамичную дидактическую концепцию, которая по мере развития и совершенствования общественных отношений, системы образования наполняется новым содержанием. Результаты рассмотренных исследований по вопросам индивидуализации обучения позволяют выделить три основных и равноправных функции индивидуализации обучения - адаптационную, развивающую и функцию реализации. С учетом обозначенных функций уточним определение индивидуализации обучения. Под индивидуализаџией обучения мы будем понимать организацию учебного процесса, направленную на учет, развитие и реализаџию индивидуальности учащуихся. Другими словами, при реализации принципа индивидуализации обучения постановка изелей, отбор содержания, выљор форм, методов, средств обучения и оченивания учебных достижений учащихся должнь 1) осуществляться с учетом индивидуальных особенностей учащиихся, 2) ориентироваться на развитие индивидуальных особенностей и 3) создавать условия для реализащии индивидуальных особенностей учащзихся в учебной деятельности.

Кроме того, мы согласны с позицией В.М. Жураковской, которая выражается в следующем. В современных условиях задача педагога состоит не в том, чтобы сформировать индивидуальность учащегося, а в том, чтобы обеспечить ее становление, чтобы передать учащемуся не саму индивидуальность как некоторую структуру, а передать механизм 
управления своей индивидуальностью, чтобы он стал субъектом формирования своей индивидуальности, опыта становления индивидуальности [4]. В свете указанной идеи индивидуализация обучения предполагает постепенный выход на самоучет, саморазвитие, самореализацию индивидуальности учащихся. Данное положение приобретает особую актуальность при разработке вопросов индивидуализации обучения на старшей ступени общего образования [16].

Установлено, что зоной ближайшего развития индивидуальности учащихся старшего подросткового и юношеского возраста является развитие их самопознания, самооценки, самообразования, самовоспитания, саморазвития, саморегуляции, самодисциплины, самоопределения, самореализации, самоактуализации $[4,6,18]$.

C учетом изложенного, a также в контексте данного нами определения индивидуализации обучения скорректируем цели индивидуализаџии обучения на старшей ступени общего образования:

1. Адаптационная функция обуславливает следующие цели индивидуализации обучения: развитие навыков самопознания, самодиагностирования, формирование адекватной самооценки учащихся.

2. Развивающая функция обуславливает следующие цели индивидуализации обучения: формирование навыков самообучения, саморазвития, самовоспитания, самодисциплины, саморегуляции.

3. Функция реализации обуславливает следующие цели индивидуализации обучения: создание условий для самовыражения, самоопределения, самореализации, самоактуализации учащихся.

Реализация всех указанных целей индивидуализации обучения предполагает развитие определенного уровня самостоятельности старшеклассников во всех сферах их жизнедеятельности.

Приведенный подход к определению понятия «индивидуализация обучения», а также содержание целей индивидуализации обучения на 
старшей ступени общего образования использовались нами при разработке модели построения математического курса по выбору, направленного на реализацию дидактического принципа индивидуализации обучения, компоненты которой мы планируем описать в последующих публикациях.

\section{Литература:}

1. Гердо Н.В. Индивидуализация обучения учащихся старших классов в современной общеобразовательной школе [Текст]: автореф. дис...канд. пед. наук / Н.В. Гердо. - Чебоксары, 2012. - 24 с.

2. Голуб Б.А. Основы общей дидактики [Текст]: учеб. пособие для студ. педвузов. / Б.А. Голуб. - М.: Гуманит. изд. центр ВЛАДОС, 1999. - 96 с.

3. Донец В.А. Развитие познавательной активности учащихся профессионального лицея на основе принципа индивидуализации обучения [Текст]: автореф. дис...канд. пед. наук / В.А. Донец. - Ставрополь, 2003. - 28 с.

4. Жураковская В.М. Структура опыта становления индивидуальности обучающегося как основание для его формирования [Электронный ресурс] / В.М. Жураковская // Мир науки, культуры, образования. - 2014. - № 2 (45). - Режим доступа: http://elibrary.ru/item.asp?id=21507086. - [Дата обращения: 20.11.2016].

5. Завалко Н.А. Теория и практика индивидуализации процесса обучения в многоступенчатой системе «детский сад-школа-вуз» [Текст]: автореф. дис...д-ра. пед. наук / Н.А. Завалко. - Барнаул, 2000. - 42 с.

6. Ивасюк О.С. Индивидуализация как фактор самообразования старших школьников (на примере обучения иностранному языку) [Текст]: автореф. дис...канд. пед. наук / О.С. Ивасюк. - Ульяновск, 2004. - 24 с.

7. Кирсанов А.А. Индивидуализация учебной деятельности как педагогическая проблема [Текст]: монография / А.А. Кирсанов. - Казань: Издательство Казанского университета, 1982. - 224 с.

8. Колишев Н.С. Индивидуально-дифференцированный подход в процессе обучения старшеклассников [Текст]: автореф. дис...канд. пед. наук / Н.С. Колишев. Москва, 1993. - 18 с.

9. Крутецкий В.А. Психология математических способностей школьников [Текст] / В.А. Крутецкий. - М.: Просвещение, 1968. - 432 с.

10. Магдиев Ю.Т. Индивидуализация обучения в комсомольских учебных заведениях [Текст]: автореф. дис...канд. пед. наук / Ю.Т. Магдиев. - Москва, 1991. $23 \mathrm{c.}$

11. Матюхова Д.В. Индивидуально-дифференцированный подход в процессе обучения старшеклассников [Текст]: автореф. дис...канд. пед. наук / Д.В. Матюхова. Кострома, 2008. - 22 с.

12. Методика преподавания математики в средней школе. Общая методика [Текст]/ сост. Р.С. Черкасов, А.А. Столяр. - М.: Просвещение, 1985. - 336 с.

13. Плигин А.А. Психология познавательных стратегий школьников в индивидуализации образования [Текст]: автореф. дис...д-ра. психол. наук / А.А. Плигин. - Москва, 2009. - 56 с. 
14. Подласый И.П. Педагогика. Новый курс [Текст]: учебник для студ. пед. вузов: В 2 кн. / И.П. Подласый. - М.: Гуманит. изд. центр Владос, 1999. - Кн.1: Общие основы. Процесс обучения. -576 с.

15. Рыбникова Е.В. Дифференциация и индивидуализация обучения предметам естественно-научного цикла с учетом когнитивно-стилевых особенностей обучающихся [Текст]: автореф. дис...канд. пед. наук / Е.В. Рыбникова. - Ярославль, 2008. $-24 \mathrm{c}$.

16. Скибина Я.В. Развитие индивидуальности старшеклассников на математических курсах по выбору [Электронный ресурс] / Я.В. Скибина // Интернетжурнал «Мир науки». - 2016. - Том 4, номер 3. - Режим доступа: http://mirnauki.com/PDF/51PDMN316.pdf. - [Дата обращения: 20.11.2016].

17. Смирнова И.М. Педагогика геометрии [Текст]: монография / И.М. Смирнова. - М.: Прометей, 2004. - 336 с.

18. Теров А.А. Педагогические условия индивидуализации образовательного процесса в старших классах сельской школы [Текст]: автореф. дис...канд. пед. наук / А.А. Теров. - Москва, 2009. - 26 с. 17

19. Унт И.Э. Индивидуализация и дифференциация обучения [Текст] / И.Э Унт. - М.: Педагогика, 1990. - 190 с. 18

20. Хабибулин Д.А. Развитие познавательной самостоятельности студентов университета на основе индивидуализации обучения [Текст]: автореф. дис...канд. пед. наук / Д.А. Хабибулин. - Магнитогорск, 2003. - 24 с. 19

21. Шмелькова Л.В. Педагогические условия реализации механизма индивидуализации обучения [Текст]: автореф. дис...канд. пед. наук / Л.В. Шмелькова. - Челябинск, 1991. - 25 с. 20

\section{References:}

1. Gerdo N.V. Individualizacija obuchenija uchashhihsja starshih klassov v sovremennoj obshheobrazovatel'noj shkole [Tekst]: avtoref. dis...kand. ped. nauk / N.V. Gerdo. - Cheboksary, 2012. - 24 s.

2. Golub B.A. Osnovy obshhej didaktiki [Tekst]: ucheb. posobie dlja stud. pedvuzov. / B.A. Golub. - M.: Gumanit. izd. centr VLADOS, 1999. - 96 s.

3. Donec V.A. Razvitie poznavatel'noj aktivnosti uchashhihsja professional'nogo liceja na osnove principa individualizacii obuchenija [Tekst]: avtoref. dis...kand. ped. nauk / V.A. Donec. - Stavropol', 2003. - 28 s.

4. Zhurakovskaja V.M. Struktura opyta stanovlenija individual'nosti obuchajushhegosja kak osnovanie dlja ego formirovanija [Jelektronnyj resurs] / V.M. Zhurakovskaja // Mir nauki, kul'tury, obrazovanija. - 2014. - № 2 (45). - Rezhim dostupa: http://elibrary.ru/item.asp?id=21507086. - [Data obrashhenija: 20.11.2016].

5. Zavalko N.A. Teorija i praktika individualizacii processa obuchenija $\mathrm{v}$ mnogostupenchatoj sisteme «detskij sad-shkola-vuz» [Tekst]: avtoref. dis...d-ra. ped. nauk / N.A. Zavalko. - Barnaul, 2000. - 42 s.

6. Ivasjuk O.S. Individualizacija kak faktor samoobrazovanija starshih shkol'nikov (na primere obuchenija inostrannomu jazyku) [Tekst]: avtoref. dis...kand. ped. nauk / O.S. Ivasjuk. - Ul'janovsk, 2004. - 24 s.

7. Kirsanov A.A. Individualizacija uchebnoj dejatel'nosti kak pedagogicheskaja problema [Tekst]: monografija / A.A. Kirsanov. - Kazan': Izdatel'stvo Kazanskogo universiteta, 1982. $-224 \mathrm{~s}$.

8. Kolishev N.S. Individual'no-differencirovannyj podhod $\mathrm{v}$ processe obuchenija starsheklassnikov [Tekst]: avtoref. dis...kand. ped. nauk / N.S. Kolishev. - Moskva, 1993. $18 \mathrm{~s}$. 
9. Kruteckij V.A. Psihologija matematicheskih sposobnostej shkol'nikov [Tekst] / V.A. Kruteckij. - M.: Prosveshhenie, 1968. - 432 s.

10. Magdiev Ju.T. Individualizacija obuchenija $\mathrm{v}$ komsomol'skih uchebnyh zavedenijah [Tekst]: avtoref. dis...kand. ped. nauk / Ju.T. Magdiev. - Moskva, 1991. - 23 s.

11. Matjuhova D.V. Individual'no-differencirovannyj podhod $v$ processe obuchenija starsheklassnikov [Tekst]: avtoref. dis...kand. ped. nauk / D.V. Matjuhova. - Kostroma, 2008. $-22 \mathrm{~s}$.

12. Metodika prepodavanija matematiki v srednej shkole. Obshhaja metodika [Tekst]/ sost. R.S. Cherkasov, A.A. Stoljar. - M.: Prosveshhenie, 1985. - 336 s.

13. Pligin A.A. Psihologija poznavatel'nyh strategij shkol'nikov $\mathrm{v}$ individualizacii obrazovanija [Tekst]: avtoref. dis...d-ra. psihol. nauk / A.A. Pligin. - Moskva, 2009. - 56 s.

14. Podlasyj I.P. Pedagogika. Novyj kurs [Tekst]: uchebnik dlja stud. ped. vuzov: V 2 kn. / I.P. Podlasyj. - M.: Gumanit. izd. centr Vlados, 1999. - Kn.1: Obshhie osnovy. Process obuchenija. $-576 \mathrm{~s}$.

15. Rybnikova E.V. Differenciacija i individualizacija obuchenija predmetam estestvenno-nauchnogo cikla s uchetom kognitivno-stilevyh osobennostej obuchajushhihsja [Tekst]: avtoref. dis...kand. ped. nauk / E.V. Rybnikova. - Jaroslavl', 2008. - 24 s.

16. Skibina Ja.V. Razvitie individual'nosti starsheklassnikov na matematicheskih kursah po vyboru [Jelektronnyj resurs] / Ja.V. Skibina // Internet-zhurnal «Mir nauki». 2016. - Tom 4, nomer 3. - Rezhim dostupa: http://mir-nauki.com/PDF/51PDMN316.pdf. [Data obrashhenija: 20.11.2016].16.

17. Smirnova I.M. Pedagogika geometrii [Tekst]: monografija / I.M. Smirnova. - M.: Prometej, 2004. - 336 c.

18. Terov A.A. Pedagogicheskie uslovija individualizacii obrazovatel'nogo processa $\mathrm{V}$ starshih klassah sel'skoj shkoly [Tekst]: avtoref. dis...kand. ped. nauk / A.A. Terov. Moskva, 2009. - 26 s.

19. Unt I.Je. Individualizacija i differenciacija obuchenija [Tekst] / I.Je Unt. - M.: Pedagogika, 1990. - 190 s.

20. Habibulin D.A. Razvitie poznavatel'noj samostojatel'nosti studentov universiteta na osnove individualizacii obuchenija [Tekst]: avtoref. dis...kand. ped. nauk / D.A. Habibulin. - Magnitogorsk, 2003. - 24 s.

21. Shmel'kova L.V. Pedagogicheskie uslovija realizacii mehanizma individualizacii obuchenija [Tekst]: avtoref. dis...kand. ped. nauk / L.V. Shmel'kova. - Cheljabinsk, 1991. $25 \mathrm{~s}$. 